\title{
МЕТОД КРУГОВОЙ ТРЕНИРОВКИ КАК ЭФФЕКТИВНОЕ СРЕДСТВО ПОДГОТОВКИ СТУДЕНТОВ К СДАЧЕ НОРМ ВФСК ГТО ПО ПРЫЖКАМ В ДЛИНУ С РАЗБЕГА
}

\section{THE METHOD OF CIRCULAR TRAINING AS AN EFFECTIVE MEANS OF PREPARING STUDENTS TO PASS THE STANDARDS OF THE WFSK TRP IN THE LONG JUMP WITH A RUN}

\section{O. Bushmanova}

A. Nikulin

E. Printseva I. Marina

Summary: The article discusses the method of circular training for the successful preparation of students to pass the TRP standards for long jump with a run, provides a set of exercises for circular training, presents the results of a study on the approbation of the methodology for preparing students of Vologda State University to pass the tests of the TRP complex for long jump with a run.

Keywords: Iong jump with a running start, students, circuit training, exercise, TRP.

\author{
Бушманова Ольга Ивановна \\ доцент, Вологодский государственный университет, \\ bush_oi@mail.ru \\ Никулин Александр Валентинович \\ К.п.н., дочент, Вологодский государственный \\ университеm, nikulinav74@yandex.ru \\ Принцева Екатерина Владимировна \\ старший преподаватель, Вологодский \\ государственный университет, \\ katrin-darts@yandex.ru \\ Марина Ирина Владимировна, \\ старший преподаватель, Вологодский \\ государственный университет, \\ miwirina@mail.ru
}

Аннотация: В статье рассматривается метод круговой тренировки для успешной подготовки студентов к сдаче норм ГТО по прыжкам в длину с разбега, приведён комплекс упражнений для круговой тренировки, представлены результаты исследования по апробации методики подготовки студентов Вологодского государственного университета к сдаче испытаний комплекса ГТО по прыжкам в длину с разбега.

Ключевые слова: прыжок в длину с разбега, студенты, круговая тренировка, упражнения, Комплекс ГТО.

них получение значка ассоциируется с получением дополнительных баллов при поступлении в вузы и сузы [3, с. 119], у других с прекрасной возможностью укрепить своё здоровье, у третьих как способ самовыражения.

В комплекс ГТО 6 ступени (возраст от 18 до 29 лет) в испытания по выбору входит прыжок в длину с разбега, относящийся к скоростно-силовым легкой атлетики.

Многолетний авторский опыт работы, проведенное исследование на базе Вологодского государственного университета свидетельствуют, что для сдачи норматива прыжок в длину с разбега на золотой значок у студентов не хватает скоростно-силовой подготовки.

В скоростно-силовых видах спорта соревновательные упражнения имеют сложную ациклическую, или смешанную структуру. Степень их координационной сложности очень высокая.

Скоростно-силовые качества, как говорит сам термин, проявляются в действиях, где наряду с силой требуется высокая скорость движений (прыжки, метания, бег на короткие дистанции и т.д.). Некоторые из таких ско-

Каждый по-своему видит пользу от сдачи ГТО. У од- 
ростно-силовых проявлений получили название взрывной силы.

Развитие скоростно-силовых способностей обусловлено в той или иной мере развитием собственно силовых способностей. Вместе с тем максимальные показатели скорости движений не связаны прямо пропорционально с максимальными пролявлениями силы.

Для увеличения результата в прыжках необходимо уделять много внимания специальным прыжковым упражнениям на травяном грунте или на песке. Очень важно научить студента правильному переходу от разбега к отталкиванию. Добиваясь выполнения правильного общего ритма разбега, необходимо обратить внимание на повышение частоты последних шагов разбега.

В прыжках высокая скорость выполнения разбега сочетается с предельным и точным проявлением усилий в финальной фазе движения. В разбеге студенты должны научиться развивать большую скорость движения без потери контроля за своими движениями и излишнего напряжения. На последних шагах разбега происходит подготовка к отталкиванию, и тут важно не сбавлять скорость перед постановкой ноги на отталкивание. У студентов вызывает затруднения сохранение скорости к концу соревновательного упражнения.

Скоростно-силовые качества и прыгучесть развиваются с помощью различных прыжковых упражнений без отягощений и с отягощением: прыжки в длину с места одиночные, тройные, запрыгивания и спрыгивания с высоты 50-70 см; подскоки, броски набивного мяча [4. c. 126].

Техника прыжка в длину изучается посредством выполнения специальных имитационных упражнений: ускорений одиночных и двойных, по ритму имитирующих разбег; разбег на беговой дорожке и перед ямой с отталкиванием; прыжков в «шаге» с пробеганием и приземлением в яму и т.д. Выполнение специальных упражнений требует к себе особого внимания и контроля со стороны преподавателя и студента. Чем больше сходство между специальными и соревновательными упражнениями, тем легче переносятся и полнее используются приобретенные навыки и качества[4. с. 126].

После проведения контрольных испытаний преподаватель должен определить, в каком направлении следует вести физическую подготовку студентов, чтобы увеличить результат в прыжках.

Круговая тренировка, осуществляемая на уроках физического воспитания, представляет собой целостную самостоятельную методическую форму занятий и в то же время не сводится к какому-либо одному методу. Она включает ряд частных методов строго регламентированного упражнения с избирательным и общим воздействием на организм занимающегося [5. с. 10-11].

Основу круговой тренировки составляет серийное (слитное или с интервалами) повторение нескольких видов физических упражнений, подобранных и объединенных в комплекс в соответствии с определенной упорядоченной схемой - символом круговой тренировки [5. с. 11].

Преподаватель распределяет студентов по 1-2 человека по «станциям» - обычно по кругу (стадион). Студенты начинают и заканчивают выполнение упражнений, переходят на другие «станции» строго по сигналу преподавателя. После прохождения круга всеми занимающимися, дается достаточно времени для восстановления, и затем это круг повторяется еще раз. Преподаватель должен замерить частоту сердечных сокращений у занимающихся, чтобы убедиться, что все восстановились и готовы к работе. Этот метод повышает моторную плотность занятия.

Все упражнения разучиваются заранее, обговаривается темп выполнения, скорость, количество повторений.

На занятиях по физическому воспитанию в вузе круговая тренировка имеет особое значение, т.к. позволяет большому числу студентов заниматься одновременно и самостоятельно, используя максимальное количество инвентаря и оборудования [6, с. 10].

В комплекс круговой тренировки, для подготовки к сдаче прыжков в длину с разбега включают имитационные и беговые упражнения скоростно-силового характера и специальные упражнения.

Специальные упражнения обязательно состоят из одного или нескольких элементов основного упражнения, соответствуя ему по форме или по содержанию выполнения. Необходимо, чтобы по форме и характеру движений, а также по психологической направленности специальные упражнения были более сходны с соответствующей частью прыжка.

Рекомендуемые упражнения комплекса круговой тренировки для подготовки к сдаче норматива по прыжкам в длину с разбега:

1. Прыжки с продвижением вперед с подтягиванием коленей к груди в быстром темпе.

2. Запрыгивание на возвышение и спрыгивание с отталкиванием двумя ногами.

3. Бег с высоким подниманием бедра на месте и с продвижением вперёд с максимальной частотой 30 секунд. 
4. Прыжки в длину с 2, 3, 5 шагов разбега.

5. Прыжки в длину с короткого разбега через планку, высота 20-40 см.

6. Многократные прыжки вверх, отталкиваясь одной ногой, поднимая другую вперед-вверх.

7. Прыжки во время бега, дистанция 50 метров, отталкиваясь на каждый пятый шаг.

8. Повторное пробегание разбега без отталкивания.

9. Тройной прыжок с места толчком двумя ногами.

10. Прыжки в длину с места на дальность приземления через препятствие (натянутая веревка).

11. Прыжки с места толчком одной и махом другой ногой с приземлением на маховую ногу и переходом на бег.

12. Метание набивного мяча вперед из полного приседа.

Цель исследования, проведенного в 2018-19 учебном году на базе Вологодского государственного университета, заключалась в выявлении эффективной методики подготовки студентов для увеличения результата в прыжках в длину с разбега.

По результатам тестирования студентов, обучающихся по специальности «Промышленное и гражданское строительство» у 67\% испытуемых вызывает затруднения сдача норматива прыжок в длину с разбега на «золотой» знак ГТО.

Всего экспериментальной работой было охвачено 45 человек (19 студентов 2 курса инженерно-строительного института специальности «Промышленное и гражданское строительство» - экспериментальная группа, 26 студентов 2 курса инженерно-строительного института специальности «Промышленная теплоэнергетика» контрольная группа).

В экспериментальной группе, на констатирующем этапе опытно-экспериментальной работы, средний результат выполнения прыжка в длину с разбега составил 382 см, в контрольной - 389 см. В экспериментальной группе каждое занятие проводилось в форме круговой тренировки. В контрольной группе студенты выполняли скоростно-силовые, специальные, беговые упражнения повторным методом, при этом плотность занятий была значительно ниже, чем при применении метода круговой тренировки.

В конце учебного года было проведено повторное тестирование.

Итоговые данные опытно-экспериментальной работы представлены в таблице.

\begin{tabular}{|l|l|c|}
\hline \multirow{2}{*}{ Этапы эксперимента } & Группы & Результаты (см) \\
\hline \multirow{2}{*}{ Констатирующий } & экспериментальная & 382 \\
\cline { 2 - 3 } & контрольная & 389 \\
\hline \multirow{3}{*}{ Формирующий } & экспериментальная & 414 \\
\cline { 2 - 3 } & контрольная & 407 \\
\hline \multirow{2}{*}{ Результат } & экспериментальная & 436 \\
\cline { 2 - 3 } & контрольная & 419 \\
\hline
\end{tabular}

Полученные результаты позволяют заключить, что в экспериментальной группе, где использовался метод круговой тренировки, значительно улучшились показатели сдачи норматив по прыжкам в длину с разбега, чем в контрольной группе, где применялся повторный метод.

Вышесказанное позволяет сделать следующие выводы:

- полученные в исследовании результаты свидетельствуют об эффективности применения метода круговой тренировки для успешной подготовки студентов к сдаче испытаний по прыжку в длину с разбега на «золотой» знак ГТО;

- предложенный комплекс круговой тренировки можно применять с целью совершенствования техники прыжков в длину с разбега;

- метод круговой тренировки обеспечивает более высокую моторную плотность занятия, что существенно повышает эффективность подготовки студентов к сдаче испытаний Комплекса ГТО и может использоваться для тренировки и по другим видам.

\section{ЛИТЕРАТУРА}

1. Готов к труду и обороне [Электронный ресурс]: Википедия. Свободная энциклопедия. - Режим доступа: https://ru.wikipedia.org/wiki (дата обращения 08.01.2021).

2. Никулин А.В. Педагогические условия деятельности спортивного клуба вуза по формированию мотивации студентов к выполнению контрольных нормативов всероссийского физкультурно-спортивного комплекса «ГТО» / А.В. Никулин, А.В. Старостина, 0.И. Бушманова // Modern Humanitits. 2019. № 6. С. 147-152.

3. Марина И.В. Исследование теоретических знаний обучающихся в вопросах всероссийского физкультурно-спортивного комплекса «Готов к труду и обороне» / И.В. Марина, В.А. Ноах // Традиции и инновации физического воспитания обучающихся образовательных организаций: Вологда, 2019. С. 119. 
4. Бушманова 0.И. Применение метода круговой тренировки при обучении студентов технике прыжков в длину с разбега // Вестник развития науки и образования: Москва, 2010. № 5. С. 126-130.

5. Бушманова 0.И. Круговая тренировка в физическом воспитании студентов: учеб. пособие для студентов вузов по дисциплине ГСЭ.Ф - физическая культура/ Вологда : Вологодский гос. технический ун-т, 2006. - 99с.

6. Бушманова 0.И. Применение метода круговой тренировки для успешной сдачи норм ВФСК ГТО по силовым упражнениям / 0.И. Бушманова, А.В. Никулин, Е.В. Принцева // Тенденции развития науки и образования: Самара, 2019. № 55-7 С. 8-11.

( Бушманова Ольга Ивановна (bush_оi@mail.ru), Никулин Александр Валентинович (nikulinav74@yandex.ru),

Принцева Екатерина Владимировна (katrin-darts@yandex.ru).

Журнал «Современная наука: актуальные проблемы теории и практики»

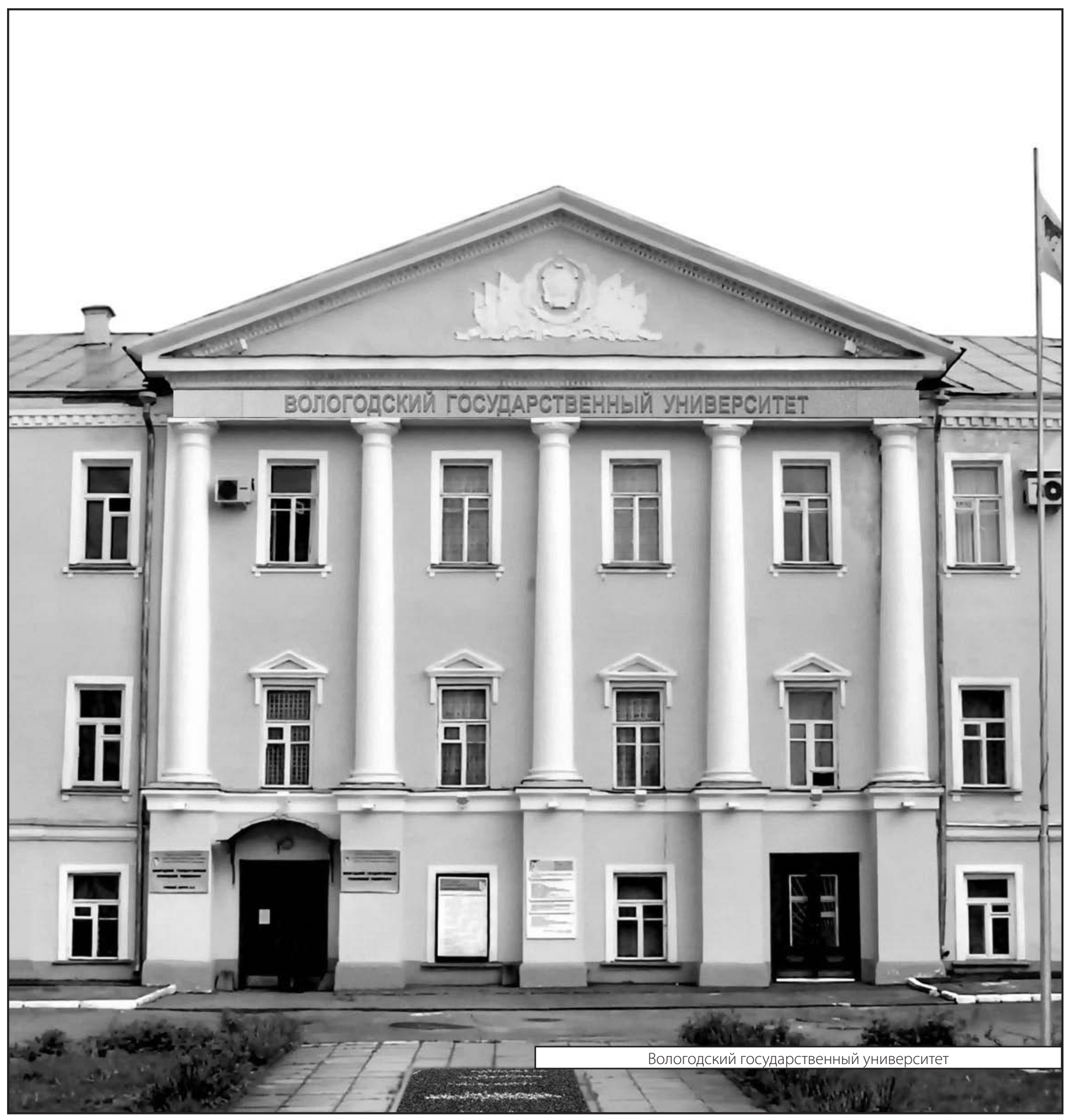

